INTERNATIONAL DESIGN CONFERENCE - DESIGN 2018

https://doi.org/10.21278/idc.2018.0452

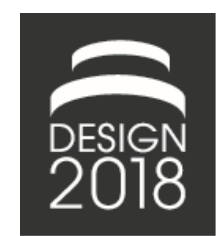

\title{
ECO-DESIGN IN THE PUPPET WORLD, A CO-LEARNING PROCESS
}

\author{
R. Allais, B. Tyl, J. Postel and R. Fleury
}

\begin{abstract}
Ecodesign has been widely explored in the development process of consumer and capital goods. This study focuses on the environmental assessment of puppets. The methodological approach is inductive and propose to adapt analytical tools from ecodesign to cultural goods specificities. First, a generic puppet design process emerged from interviews of 6 puppet makers. Then, a life cycle inventory study is performed and main environmental issues are discussed. Finally, crossfertilization between puppet design and engineering design are highlighted in research perspectives.
\end{abstract}

Keywords: cultural goods, ecodesign, case study, collaborative design, life cycle assessment (LCA)

\section{Introduction}

Eco-design is the integration of environmental constraints in the development process of product design (ISO 14062). Eco-design has been widely explored in the world of manufactured product, and it is now integrated in every major industrial sectors, from fast-moving consumer goods industries, to the building, agricultural and energy sector. Today, professions question their impact on the environment, and more generally on sustainability, constrained by regulations, market opportunities or in a voluntary approach of social responsibility of the organizations (Van Hemel and Cramer, 2002; ISO, 2009).

The world of performing arts is also questioning its activities in regards to sustainability with the publication of CSR reports on musical, theatre or dance festivals. Carbon footprint have been widely performed so far and economical evaluation of direct, indirect and induced benefits of such events have also been completed (Mitchell, 1993; Négrier and Vidal, 2009). Nowadays, local or biological sourcing for the catering, alternative transports for publics or waste management are quite common.

Despite interesting specific practices to reduce the environmental impacts of products developed for cultural events, there are very few researches on the ecodesign of cultural goods and it is still quite complex to identify good practices in this sector.

In 2015, the Centre national des arts du Cirque in Châlons-en-Champagne (France) and the Institut International de la Marionnette in Charleville-Mézières (France) have created the chair ICiMa (Innovation in Circus and Puppetry) to lead research programs that aim at developing their arts, but also at stressing the impact of these arts on their regional territory. In this context, ICiMa initiated a research program on the life cycle of materials used in performing arts, especially puppetry and circus. The initial motivation was, on the one hand, to bridge the gap between puppet makers' way of living and aspirations (e.g. environmental sensitivity, veganism, etc.) and the un-healthy and un-environmental materials they use in their workshops (i.e. chemical product or petrol-based material, etc.). On the other hand, this 
reflexion on material also targets to preserve future heritage of these arts from self-destruction (e.g. foam-based puppets disintegrate in few decades) (Fleury and Thomas, 2016).

The first step of this project on long-lasting and greener materials was to experiment with the plastic and dramaturgical properties of folded and crumpled paper (Rohmer et al., 2014). Researchers, directors and puppeteers collaborated to explore the emergent mechanical and esthetical properties due to crumpling and folding of a traditional material (paper). This "new" material appears of high interest for scenography, as it is easy to transport and store, cheap and with -supposedly- lower environmental impacts than usual materials. At this point, two eco-design researchers were involved in the project with the initial demand from the chair ICiMa to find alternative materials to foam and chemicals and extend the reflexions on environmental footprints of puppetry.

The main objective of this paper is to propose a narrative of the process of co-learning and crossfertilization of puppetry arts and eco-design research.

- This communication first provides insights on puppets as cultural goods and presents examples of eco-design strategies of scenery.

- The second part presents the co-learning process to understand the puppet development process and the methodology to assess environmental impacts of the puppets and co-design alternative solutions (initial objective).

- The third section presents results of the experimentation: a generic model of the puppet development process, main insights from the environmental assessments and evolution of the perimeter and objectives of the research.

- The last section discusses the cross-fertilization of these two sectors and proposes perspectives for future research in product design and eco-design.

\section{The puppet as the object of analysis: State of the art and practices}

A seminal definition of a puppet is a "figure of wood, cardboard, cloth or other material, representing a person or animal, whether articulated or not, hand-operated (puppet sheath) or with the aid of threads (marionettes) by a person [...]." (CNRTL, 2017). A puppet is different from a doll (i.e. that is not front of a public), an automaton (i.e. that can work even without public) or a statue (i.e. not animated).

Puppets are functional artisanal products with high artistic, symbolic and patrimonial values. In fact, according to the definition of UNESCO and ITC (1997), artisanal products are "those produced by artisans, either completely by hand or with the help of hand-tools or even mechanical means, as long as the direct manual contribution of the artisan remains the most substantial component of the finished product... The special nature of artisanal products derives from their distinctive features, which can be utilitarian, aesthetic, artistic, creative, culturally attached, decorative, functional, traditional, religiously and socially symbolic and significant".

ICiMa chair has a preservation mission for puppetry and consider puppets as cultural goods that are "consumer goods that convey ideas, symbols and ways of life, i.e. books, magazines, multimedia products, software, recordings, films, videos, audio-visual programmes, crafts and fashion" (UNESCO, 2009). In addition, according to European Commission "cultural goods means any object which is of importance for archaeology, prehistory, history, literature, art or science [...] and meets the minimum age threshold specified therein". For objects of artistic interest, as puppets, the minimum age threshold is more than 250 years (European Commission, 2017).

According to an extensive literature review in multiple scientific databases in social science (Cairn, Persée, Jstor) or engineering science (Scopus, Elsevier, Springer), there is currently no publication linked to the keywords \{'environmental impacts' or 'LCA', 'sustainability' or 'ecodesign'\} and \{'puppet' or 'marionette' or 'art piece' or 'cultural goods' or 'craftsmanship'\}. One possible reason is that environmental analysis are above all applied to consumer's goods and capital goods, as defined by the Encyclopaedia Britannica (2017) (italics in Table 1). More, one can question the pertinence of assessing environmental impact of a single artistic artefact compared to impacts of consumer goods. In fact, the impacts associated with these unitary products are derisory, but this should not prevent puppetry professionals - who are really in demand - from understanding the impacts of their activities and then seeking solutions to minimize these impacts. 
Table 1. Consumer, capital goods and puppets

\begin{tabular}{|c|c|c|c|c|c|}
\hline \multirow[b]{2}{*}{ 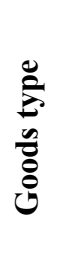 } & \multicolumn{3}{|l|}{ Consumer goods } & \multirow[b]{2}{*}{$\begin{array}{l}\text { Capital goods } \\
\text { (tangible items } \\
\text { such as buildings, } \\
\text { machinery, and } \\
\text { equipment) }\end{array}$} & \multirow[b]{2}{*}{$\begin{array}{l}\text { Puppets (functional } \\
\text { artisanal products } \\
\text { and cultural goods) }\end{array}$} \\
\hline & $\begin{array}{l}\text { Durable goods } \\
\text { (automobiles, } \\
\text { furniture, } \\
\text { household } \\
\text { appliances, and } \\
\text { mobile homes) }\end{array}$ & $\begin{array}{l}\text { Non-durable } \\
\text { goods (food, } \\
\text { beverages, } \\
\text { clothing, shoes, } \\
\text { and gasoline) }\end{array}$ & $\begin{array}{l}\text { Services } \\
\text { (haircuts, auto } \\
\text { repairs, and } \\
\text { landscaping) }\end{array}$ & & \\
\hline 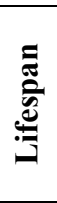 & $\begin{array}{l}\text { significant, often } \\
\text { three years or more }\end{array}$ & $\begin{array}{l}\text { ranging from } \\
\text { minutes to three } \\
\text { years }\end{array}$ & \multirow{2}{*}{$\begin{array}{l}\text { intangible } \\
\text { products or } \\
\text { actions that } \\
\text { are typically } \\
\text { produced and } \\
\text { consumed } \\
\text { simultaneously }\end{array}$} & $\begin{array}{l}\text { significant, often } \\
\text { three years or } \\
\text { more }\end{array}$ & $\begin{array}{l}\text { Cultural goods (at } \\
\text { least } 250 \text { years), } \\
\text { centuries (in } \\
\text { museums) for some } \\
\text { of them }\end{array}$ \\
\hline ن̃ & $\begin{array}{l}\text { spread over its life } \\
\text { span, which tends } \\
\text { to create demand } \\
\text { for a series of } \\
\text { maintenance } \\
\text { services }\end{array}$ & $\begin{array}{l}\text { immediate or } \\
\text { almost immediate }\end{array}$ & & $\begin{array}{l}\text { produced and used } \\
\text { in the production } \\
\text { of other goods and } \\
\text { services }\end{array}$ & $\begin{array}{l}\text { Rehearsals (months) } \\
\text { and performances } \\
\text { (up to } 30 \text { years } \\
\text { depending on the } \\
\text { show programming) }\end{array}$ \\
\hline
\end{tabular}

Despite the lack of scientific literature for environmental assessment of handcrafted goods designed for an artistic event, good practices have to be pointed out. These example concern scenery, that are, as puppets, artisanal products designed for artistic events.

Scenery are material intensive (mainly steel, wood, and polystyrene) for a short use phase (rehearsal and performance). Different strategies to extend the lifespan, use and end of life of scenery emerged to face the massive (at an event scale) production of waste linked to this activity. As an example, Festival d'Aix produces 39 tons of waste per year mainly connected with scenery production/destruction. In 2014, the Festival of Aix-en-Provence also launched an R\&D project for the eco-design of their scenery. $\mathrm{CO}_{2}$ emissions, health preservation and cost reduction are the criteria to select the best tactics to apply amongst the numerous they considered (i.e. bio-based material, mono-material, standard for technical elements, modular design...). Unlike the material approach from the initial puppetry project, festival d'Aix adopt a life-cycle perspective and the solutions put in place concern both the supply chain, the waste management at the workshop level via new design practices. In 3 years, they were able to deploy an environmental management system and propose an eco-designed scenery (Eco-manifestations, 2017).

In response to the destruction of scenery at their end of use, Artstock is an association that proposes to recover and reuse various elements coming from the artistic production (e.g. scenery parts and costumes,). It is now the first European platform dedicated to the upcycling and reuse of live performance and audio-visual staging elements (Artstock, 2017).

Researchers implied in this project proposed to extend the initial question on alternative materials to a whole life-cycle approach to evaluate what were the main impacts of a puppet comprising - but not limited to - natural environment, health, resources.

\section{Methodology}

The team was composed of 4 researchers and 6 puppet makers. Two researchers have mechanical or production engineering background and a strong expertise on eco-design methods and tools. Two researchers, from the ICiMa chair, have a strong background in history, theories and pedagogies of puppetry. Puppet makers develop individual knowledge linked to their artistic careers and practices and have a strong expertise on the lifecycle of their creations. Regarding that eco-design researchers had no knowledge on the "Puppet Development Process" (PuDP), its specificities, and the lack of literature, they adopted an inductive reasoning (i.e. from specific observations to general hypothesis and/or models). Consequently, to meet the objective of reducing puppet's impacts, eco-design researchers had 
first to understand the PuDP, then to point out what the main impacts of this process are, share with puppet makers to finally explore together solutions to reduce these impacts.

This research is explorative and constructed upon a co-learning process described below.

- Knowledge pooling. Researchers from eco-design and puppetry exchanged basic knowledge on environmental assessment (e.g. life cycle approach etc.) and puppetry issues (e.g. health, conservation etc.) in order to create a minimal pool of shared knowledge.

- Puppet makers' recruitment. The goal was to bring together different generations of makers, construction approaches, training paths, puppet techniques and types of materials.

- Life cycle inventory tool development. It is based on the generic life cycle of consumer goods that has been adapted for the puppet-show couple a priori. Iterations were carried out between eco-design experts and puppet researchers from the ICiMa chair for LCI tool validation.

- Co-learning process. Semi-structured interviews of puppet makers were performed (from $1 \mathrm{~h} 30$ to $2 \mathrm{~h}$ ) in which each puppet maker proposed a narrative of previous or on-going project. For the design researchers, the purpose was to understand the PuPD and interactions between the puppet design and the show. (See Section 3.1 - on the design process). For puppet makers, interview was an opportunity to formulate their motivations, questions or concerns about the project. Then the LCI tool was detailed to the puppet makers with a particular emphasis on the main concepts: life cycle approach, bill of material, energy input/output etc. During those interviews, a researcher on puppetry was documenting the process and eased mutual understanding.

- Life Cycle Inventory. Puppet makers filled out the tool in autonomy then a second individual interview (duration $1 \mathrm{~h}$ ) has been performed to review the grid, complete it if necessary and identify hotspots to discuss during the collaborative workshop. Puppet makers evaluated the tool regarding its ease of use and utility and the completion time. Based on the criticism of the puppetcentred approach, new perspectives emerged (show/workshop/performance-centred approach etc.)

- Collective workshop (half a day) sharing of analyses with the makers and formulation of improvement tracks both on the analysis grid and construction practices. Puppet makers brainstormed and exchanged on their issues and best practices at different system levels: puppet, workshop/residency, performance/tour, puppet community and society.

\section{Experimental results and initial analysis}

This section exposes experimental results of the project. First, the puppet design development process is modelled based on initial knowledge pooling then sharpened with interviews of puppet makers and result with the adaptation of the standard life cycle of a consumption product. Puppet makers then completed an input/output inventory and provided detailed information on their design rationale during discussions around an adaptation of a LCI tool. Finally, the multi-level analysis model ambitions to support the systemic analysis of puppetry thanks to the collaborative workshop.

\subsection{On the Puppet Development Process (PuDP)}

Strong correlation between the puppet and the show emerged during interviews. Puppet can be created for a particular show or a show can be created around an existing puppet. Therefore, the first emerging issue was to understand design interactions between puppet design and staging and the multiple iterations induced by the co-evolution of these systems (Figure 1) to create a generic Puppet Development Process (Figure 2).

In this generic process, (competencies) are considered instead of specific actors because the same individual can perform several roles at the same time. Makers create their own aesthetic worlds, master one or multiple building techniques (e.g. paper, foam, and textile) and commonly develop their own processes, tools and knowledge for (Construction). The process of learning new techniques comes either from the maker as part of his personal, aesthetic research or specific demand from a director. (Expertise) is required for learning specific techniques (e.g. ceramic, glass, composites). (Staging) is the coordination between action, characters and scenography at the service of dramaturgy. 
(Scenography) is the realization of scenery, visual or sound effects, accessories etc. (Manipulation) is the puppet operation by professional manipulator or comedian.

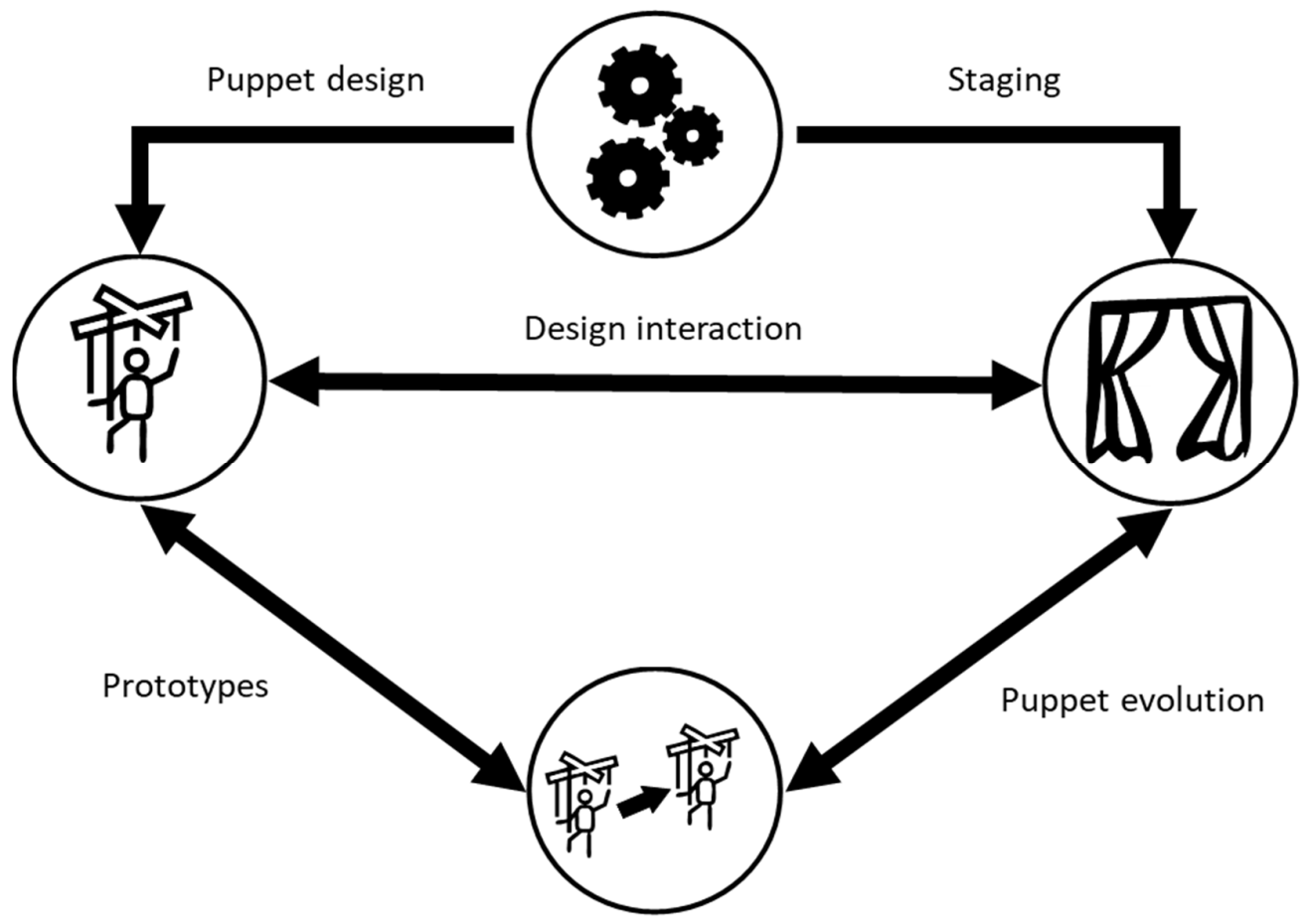

Figure 1. Co-evolution in puppet design and staging

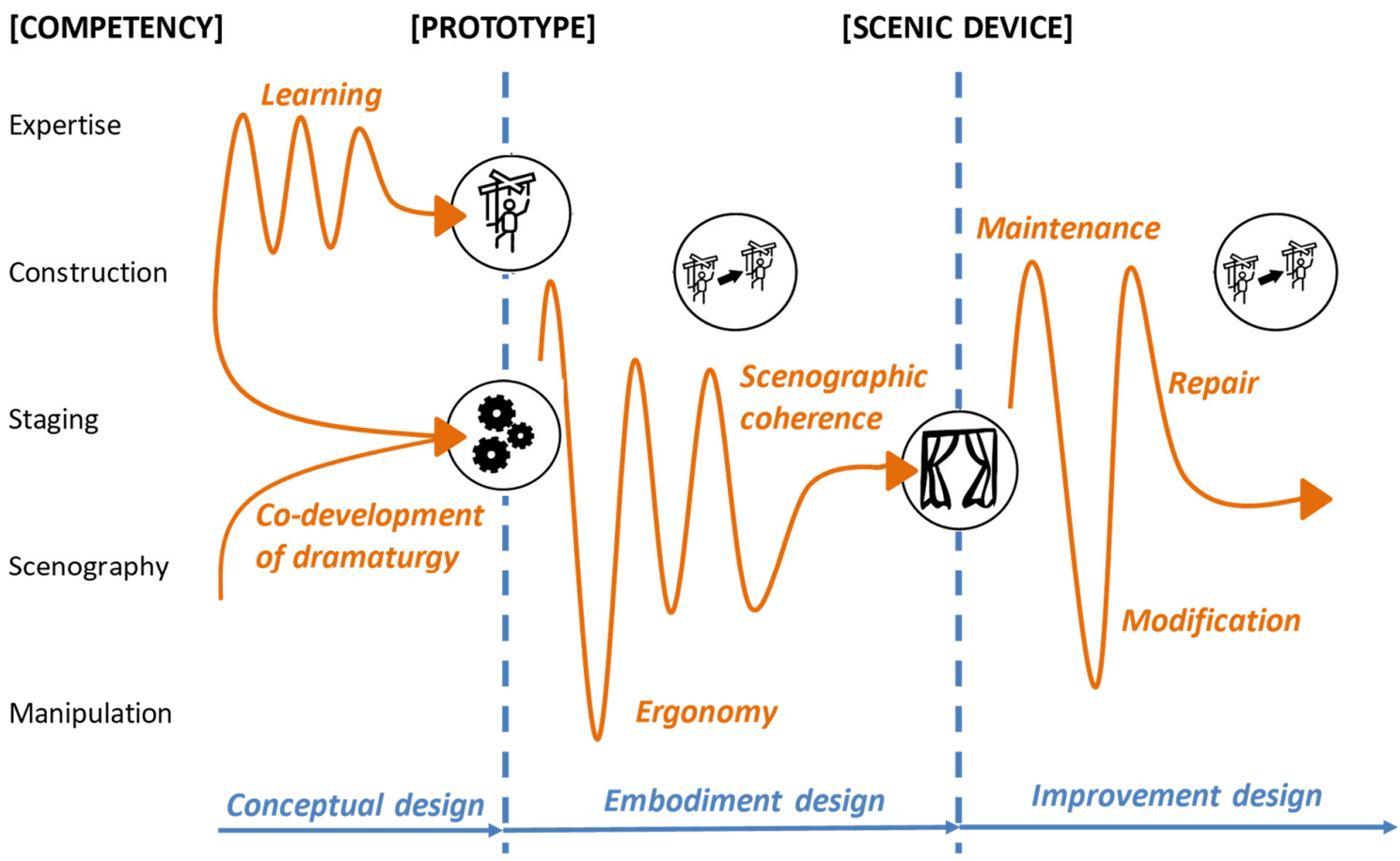

Figure 2. Generic design process

The 'learning' stage describes the learning of new techniques for specific requests or the need to continuously broaden the range of techniques mastered by the puppet maker. The learning process can 
mobilize highly skilled experts and is a major part of the artistic proposition (as an example of scientificbased puppet creation, the meta-carpe company (http://lametacarpe.com/)).

The 'co-development of dramaturgy' stage describes the collaborative process between the puppet making, the staging and the scenography to converge towards a common universe. Interactions are of different natures: aesthetic (i.e. the criteria 'distance to the public' plays an important role on the level of detail of the puppet, on the relative size of decors and puppet), on the functionalities (i.e. degrees of mobility of the puppet, type of manipulation techniques etc.). Depending on the habits of each participant, these multiple iterations can result on functional or aesthetic prototypes to validate the movements and/or particular crucial aspects of the puppet (e.g. puppet face), structural models to puppet animation, storyboards etc. There is strong collaboration and cross-fertilization of the visions during the dramaturgy development phase. This can be assimilated to 'conceptual design', early phase of a seminal product development process.

The 'puppet prototyping' and 'development' are continuous processes during which adjustment to the manipulator morphology to avoid ergonomic issues and musculoskeletal problems or allergies. When the prototype is released, the development phase can be assimilated to 'embodiment design' with the integration of constraints from the environment of the puppet (manipulation, scenography etc.). Then, during the use phase, preventive maintenance and reparation are done but, in addition, one can consider evolution of the dramaturgy, modifications of the puppet as upgrading or 'improvement design'.

Regarding business model and propriety transactions, puppet makers are usually remunerated for the development of the puppet, and they sometime propose maintenance and/or repair services (e.g. refresh the painting of a face or rebuilt a mechanism). Even if it is not the purpose of this paper, puppet makers' remuneration questions the calculation and evaluation of their work. At the end of the tour, either the puppet maker can recover his creation or the puppet can stay in the company. The show, as a creative process, is also subject to changes over time and puppets are modified from one performance series to another.

\subsection{On the Life Cycle Inventory (LCI)}

Life Cycle Assessment (LCA) is a reference for the environmental impacts analysis of consumer goods (Nissen et al., 1997; Valkama and Keskinen, 2008) as "LCA addresses the environmental aspects and potential environmental impacts (e.g. use of resources and the environmental consequences of releases) throughout a product's life cycle from raw material acquisition through production, use, end-of-life treatment, recycling and final disposal (i.e. cradle-to-grave)" (ISO, 2006). Nevertheless, due to lack of resources to perform a complete LCA, this study was limited to Life Cycle Inventory (LCI) and interpretation. An LCI study is a "phase of life cycle assessment involving the compilation and quantification of inputs and outputs for a product throughout its life cycle" (ISO, 2006).

Following the LCA methodology, the first aim of the development of the LCI tool was to determine the perimeter of the study. As the initial focus was on materials, the perimeter was limited to the puppet itself in a cradle-to-gate approach (i.e. from the raw material extraction to puppet delivery). This was quickly deemed insufficient regarding the particular nature of puppet (i.e. an artisanal cultural good) and the initial results on the PuDP presented above. Therefore, starting from a generic lifecycle with 6 stages (i.e. raw material extraction, material proceeding, product manufacturing, distribution, use, endof life), the life cycle model evolved to meet the specificities of the puppet-show system (Figure 3 ). The use phase was divided into rehearsal, performance, repair/maintenance and modification/upgrading to fit with the PuDP model.

Puppet makers were asked to fill the form in autonomy after a short individual briefing (10-15 minutes) during the first interview ( 1 excel sheet by life cycle stage). The LCI tool is based on the life cycle presented above. Puppet makers were also invited to explain their design rationale (e.g. how they choose their material, architecture, assemblies) and to add all relevant issues/comments in order to initiate future discussions.

Only few observations from the LCI tool are presented here (astonishment report). For the material acquisition phase, a large variety in the raw or semi-finished material are used for puppet making (e.g. textile, clay, plaster, leather, steel, plastic tubes, electrical wire, paper, latex, foams, straw, carton 
etc.). These materials are bought in specialized shops for professional material (e.g. clay, latex or mattress foam), supermarkets or charity shops, reused from previous shows or theatre accessories (e.g. leather or decors parts), recovered/exchanged with other puppet companies or industrial companies (e.g. leather, foam) or even gleaned from nature (e.g. tree leaves). Material selection criterions are aesthetic (e.g. texture, transparency, "right consistency"), cost, intrinsic material properties (e.g. lightness, robustness, reliability, ease of processing, water resistant) or habit: "according to learned technique".

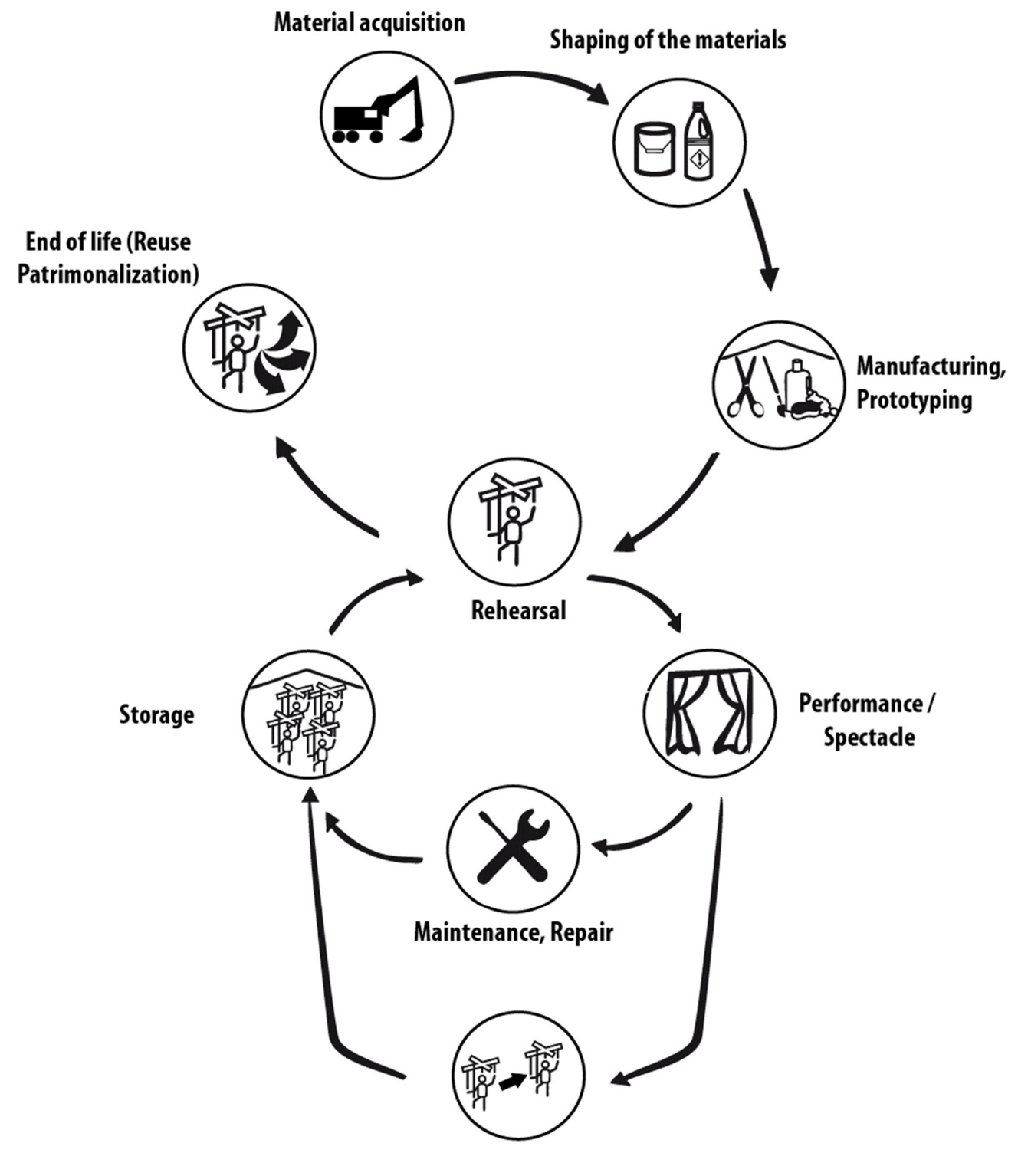

Modification, Upgrading

Figure 3. Generic life cycle of the puppet-show system

The interviews underlined that the recovery and diversion of materials/objects is a common practice in the puppet making. In addition, exchanges and donations are common both for materials and for knowledge related to puppet design: "for this phase of work, I worked in collaboration with a professional ceramist, in his workshop".

The interviews also revealed various threats related to the health of makers: toxicity of chemical products, dust from material processing and for manipulators as stated before (i.e. allergy, ergonomy 
issues). Puppet makers do not usually use adapted protections (some never did) during the processing phases (material shaping and fabrication/prototyping). On six interviewees, only one maker wears cartridge respirator when processing chemicals (e.g. paintings, neoprene gluing) or sanding wood or foam. The others "work in an airy place as much as possible" or "paint outside".

In addition to health issues, the creation process (conceptual design) requires multiple iterations "this part of the body has been reworked twice: a first tries with an elastic binding the legs (not effective) and a second, definitive, with straps attached to a transverse rod at the pelvis level". Prototyping creates scrap and waste and contribute to material consumption. A puppet maker reports, at least, four prototypes for her project: one for the aesthetic validation of the head, one for the scale validation and two prototypes before the final puppet. Puppet makers store material scrap (e.g. wood, clay, etc.) and prototypes in their workshops for a future use.

The use stage for a puppet alternates rehearsals and tours. The main hotspots related to these stages are energy consumptions and logistics related to rehearsals, artist residencies and tours. As an illustration, a spectacle developed and performed in the Balkans needed $15000 \mathrm{~km}$ by plane, $2500 \mathrm{~km}$ by train and $800 \mathrm{~km}$ by bus. The maker integrates these constraints in the design of his puppets and scenography in order to carry them in only two suitcases. During the tours, puppets are maintained and repaired (i.e. cleaning, painting, sewing...). Between tours, the puppet is stored either in the manufacturer's workshop or in the premises of the company. Puppet will evolve to adapt to the spectacle evolutions (e.g. dramaturgy, new performers etc.).

As an artisanal product, its makers do not consider a puppet as a waste after the use phase. When a show is abandoned, puppets are sometime reused in new shows with required upgrades (e.g. new mobility, aesthetic). Puppet maker are conservative and, when they can, they store their creation at their workshops or the companies who bought it store them. In only one case, the puppet maker considers her creation as "an order from a company" and did not really care about it when delivered. As a cultural good, puppets may create additional cultural value after the use phase by the patrimonialization process through private collections or public institutions (see for instance National Library of France, n.d.).

Although material was at the centre of the concerns of the makers, current practices (i.e. reuse, recover and divert) are already virtuous. The amount of material is very weak but hotspots on the health of makers and performers then the energy consumption during rehearsal and tours emerged.

The feedbacks from makers underlined that the material-oriented approach or the life cycle thinking are not adapted to the puppet development process while an architectural and/or chronological narrative appears more in line with the puppet maker thinking. Nevertheless, this tool appears as a good support for discussion as it enabled co-learning during interviews.

\subsection{On the systemic analysis of the puppet design}

The last step of this research consisted in developing a workshop regrouping the different puppet makers with the researchers. Puppet makers collectively confronted their points of view, practices and experiences in regards of the environmental approach. In parallel, they presented their puppet as well as the context of fabrication. Therefore, this workshop proposed to puppet makers to position their issues on 5 different levels of analysis then to formulate proposition at these various levels (Figure 4).

At the puppet level. The crucial hotspot in the puppet making process is the impact on makers' health by toxic chemical materials. Therefore, there is a need to use in priority no dangerous materials and to respect the use policy of these materials (e.g. wear protection devices). According to puppet makers, their lack of protection is mainly due to the lack of information, but also to the kind of gestures they have to perform during construction (high precision, repetitive and long tasks). Moreover, the economic model does not allow enough investments to equip a safe, ideal workshop regarding the multiple techniques (wood, textile and paper shaping, as well as metal, plaster, resins and other synthetic materials). This situation, that prevents responsible comportment to face health threats, encourages them to consider that there is a real need for finding alternative materials and/or researching on the ergonomics of protections. Even if exchanges of materials and knowledge are common, puppet makers consider that these good practices must be generalized, structured, and taught. The second hotspot was about ergonomics and a proposition was to adapt, when possible, their making process in order to avoid too repetitive tasks (e.g. manual foam grinding) and do stretching exercises to avoid 
musculoskeletal problems. One puppet maker directly develops his own tools to gain in performance and ergonomics.

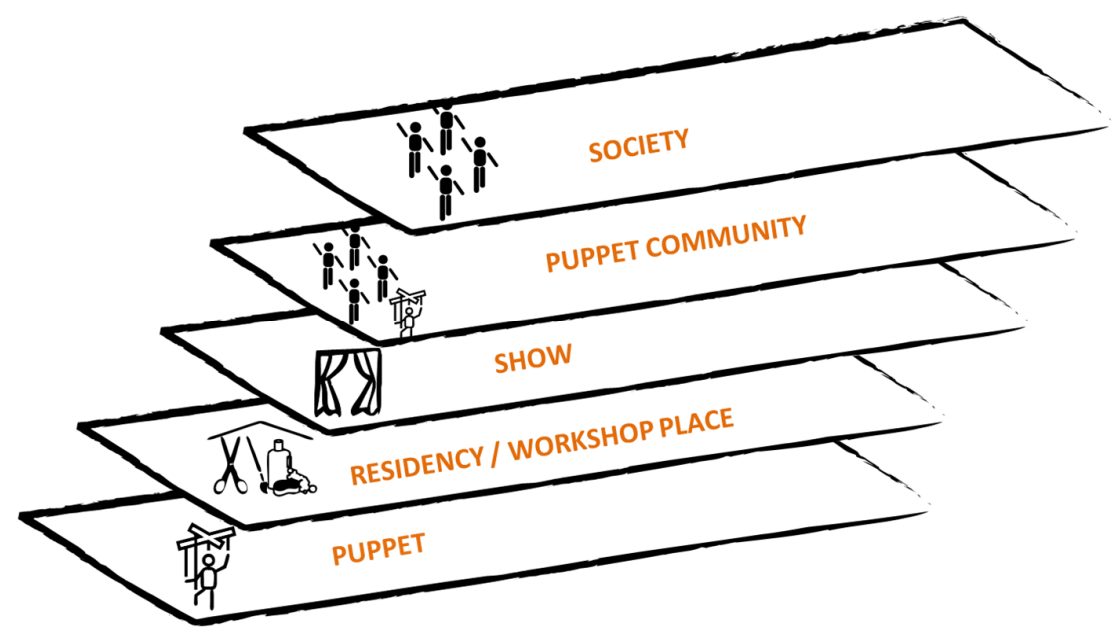

Figure 4. Levels of analysis of the system

At the workshop level, the main point discussed concerned the tension between the need to develop an artistic project and the need to travel in order to be funded and to be scheduled in festivals. The residencies are also important to develop the professional network. As one maker said, "travels is part of our profession". The second key point was about the cost of protection equipment that are supported by puppet makers (e.g. extractor hood). Moreover, when working in artistic residency, protection equipment are not always available.

At the show level, the major environmental impact is obviously due to travels. Puppet makers identified the logistic constraint but the all-in-a-suitcase solution is not replicable for every production. Another interesting point was about the health of performers. It is still today a taboo subject but some problems emerged such as the working position and associated musculoskeletal problems, and also the different allergies due to the use of petroleum-based foam, dust etc.

At the puppet community level, participants underlined that puppet is an on-going art with constant innovations. The network of puppet practitioners must be structured with common projects (e.g. research on musculoskeletal problems). The role and contributions of external observers in a fast changing artistic domain was also questioned as one consider a risk of "freezing" the practices and the innovation potential of artists.

At the society level, participants questioned the link with public actors and their role in terms of communication and valorisation of artistic projects (e.g. patrimonialization of puppets). More generally, the workshop raised the question of created value in the puppet making.

As a conclusion, this explorative research highlighted the potential impacts of the puppetry on the natural ecosystems (mainly logistics), relativized the impact of puppetry regarding consumption goods (very low amount of material) but put forward health issues both on makers and users of puppets. These results confirm the research action strategy of the chair ICiMa with the creation of a material library dedicated to puppetry, courses and training for the safe use of chemical etc. In addition, the multi-level analysis also resulted in underlining the different positive externalities. In fact, one must relativize the environmental impact of puppet making and more generally open the debate on other values, such as the cultural, societal or territorial value of such artistic activity.

\section{Discussion}

The question of appropriateness of using eco-design tools for a unitary artisanal product must be raised. In fact, it is clear that facing the massive resource consumption and emissions due to consumption products, the pertinence of spending time exploring puppetry may appear as a loss of time. However, this research opens opportunities both for the puppetry and eco-design research. 
An inductive approach was deployed for this experimental and explorative research project. We did not have a research question when the project started, we propose to experiment our eco-design tools and knowledge on the puppets. The main challenge was to continuously adapt the method to the emerging issues and problematics. The process of co-learning between puppet makers, puppetry researchers and eco-design researchers was exposed above. Intermediate results as the design interactions between multiple competencies emerged and were modelled in the PuDP. Similarities and differences between consumption products and artisanal functional cultural products were also underlined.

LCA tools appears helpless facing cultural products. In fact, the concept of functional unit is not applicable to products like puppets that create intangible value more than tangible, measurable performance. More, the structure of LCA tools are products' bill of material or material flows but in this particular case, for artisanal artistic products with iterative development process, it appears that alternative approaches may be more efficient and adapted. Chronological and/or architectural narration appears interesting and may contribute to a revision of data collection in consumer's product.

As previously said puppet makers often find their raw material in specialized workshop but also from charity shops or reused from previous shows. Therefore, they are involved in a local sourcing process, with constrained and limited resources, and they design their puppet according to the material they have found. This process refers in engineering design to local design (Tyl et al., 2015a) but also to the frugal innovation (Radjou et al., 2012). Frugal innovation refers to doing more with less because of resource scarcity or the need of resource-constrained customers (in terms of technology, finance, or materials) (Hossain et al., 2016). The analysis of the puppet design process can bring to designers some feedbacks to integrate frugality and local sourcing in the design process of consumer goods.

Another key stage in the product life cycle is the end-of-life. In consumer goods, end-of-life refers to the $3 \mathrm{R}$ approach, i.e. the recycling of materials, the reuse of the products (or some part of the product) and the reduction of consumption. Therefore, the eco-design approach is clearly oriented towards these design strategies such as remanufacturing (Lund, 1996) or repair (Tyl et al., 2015b). Cultural goods propose an alternative way to think about the end-of-life. Indeed, there is no real end-of-life of puppets but various use cycles and various value creation cycles. Moreover, puppets can continuously create cultural value through the patrimonialization process. This way of thinking can be relevant in engineering design to develop long-lasting product. Moreover, in engineering design, methods such as upgradability propose to increase the value lifetime of the product, improving a product step-by-step with the integration of upgrades (Pialot et al., 2012). In puppet design process, makers rarely explicit their process and often upgrade and repair their puppet without specific design methods. Exchanges between current eco-design methods (for remanufacturing, repair, etc.) and puppet makers' practices can be an interesting research perspective.

To finish, new trends in design process involve the Do-It-Yourself (DIY) approach, i.e. "a more democratic design process of self-driven, self-directed amateur design and production activity carried out more closely to the end user" (Atkinson, 2006). DIY design process is related to personal production and shares common feature. So DIY approaches and puppet design can also enrich each other to tend toward more sustainable practices. As an example, Bonvoisin et al. (2017) identified 14 design principles for a DIY production, such as "use modular design", "use of processes that can be performed with standard tools", "facilitate for flexible construction", "choose reversible over permanent joining features", "ensure ease of handling and transportation". These principles have been identified though the observation of makers and DIY practitioners, who often work on consumer goods, and could be enriched through the expertise of puppet makers, who work on cultural goods.

Therefore, an on-going project consists in supporting two puppet makers in the development of their puppets, to better analyse their design rationale and to better formalize their knowledge. The objective is to understand the different criteria puppet makers take into account (aesthetic, ergonomic, cost ...), the different "critical spots" during the making process (reparability, reuse, handling...), in order to imagine future specifications for puppet makers.

This study initially focused on the environmental impacts of a cultural good but finally questions the importance of this dimension regarding sustainability. In fact, even if puppet consumes resources, it contributes, as a cultural good, to Human development with the creation and diffusion of cultural capital (Bourdieu, 1979). When considering Human development as the main objective of sustainability while 
respecting planetary boundaries (Allais et al., 2017), one can consider the cultural value created by puppets more significant than the limited environmental negative externalities. Environmental impacts of puppet and shows have to be decreased but positive externalities have also to be considered and valued. The tendency, for eco-design project, is to value the reduction of the environmental impacts whereas the question of the social utility of a consumption product is rarely asked. On-going research aims at understanding interactions between cultural events and their territory and their contribution to sustainability. This upcoming research is based on the analytical framework for territorial project (Gobert and Allais, 2017) previously deployed for the analysis of PSS project for small household equipment.

\section{Acknowledgment}

Authors want to thanks the Region Nouvelle-Aquitaine as well as the European Regional Development Fund for their support. They also want to thanks the Institut International de la Marionnette and the Centre national des Arts du Cirque through ICiMa (chair for Innovation in Circus and Puppetry) supported by the Region Grand Est, the Department of Marne and of Ardennes, the Communautés d'Agglomération de Châlons-en-Champagne et d'Ardennes Métropole. And last but not least the puppet makers who participated to this research: Aline Bordereau, Michaël Cros (Cie la Méta-carpe), Ma Fuliang (Cie du Petit Cheval), Fleur Lemercier (Cie Fleur Lemercier), Irene Lentini (Teatro della Rondine), Clément Peretjatko (Cie Collapse).

\section{References}

Allais, R., Roucoules, L. and Reyes, T. (2017), "Governance maturity grid: a transition method for integrating sustainability into companies?”, Journal of Cleaner Production, Vol. 140 No. 1, pp. 213-226. https://doi.org/10.1016/j.jclepro.2016.02.069

Artstock (2017), L'association qui euvre pour la valorisation et le recyclage des décors de scène. [online] Artstock. Available at: https://artstock-asso.fr/ (accessed 09.12.2017).

Atkinson, P. (2006), "Do it yourself: democracy and design", Journal of Design History, Vol. 19, No. 1, pp. 1-10. https://doi.org/10.1093/jdh/epk001

Bourdieu, P. (1979), "Les trois états du capital culturel", Actes de la recherche en sciences sociales, Vol. 30, pp. 3-6.

Eco-manifestations (2017), Décors de spectacle: collaborer pour mieux éco-concevoir. [online] Ecomanifestations. Available at: http://www.eco-manifestations.com/eco-conception-des-decors.html (accessed 09.12.2017).

European Commission (2017), Regulation of the European parliament and of the council on the import of cultural goods, European commission.

Festival d'Aix-en-Provence (2017), "Restitution du laboratoire d'éco-conception des décors", Pôle Eco-design.

Festival d'Aix-en-Provence (n.d.), Démarche de développement durable, Rapport RSE 2012-2016, Festival International d'Art Lyrique d'Aix-en-Provence.

Fleury, R. and Thomas, C. (2016), ICiMa, chaire d'innovation sociale et territoriale. [online] Châlons-enChampagne: Cnac / Charleville-Mézières: IIM. Available at: https://icima.hypotheses.org/materiaux (accessed 09.12.2017).

Gobert, J. and Allais, R. (2017), "Intellectual and Territorial Capital for the sustainability assessment of a servitization project", ECIC2017, 9th European Conference on Intellectual Capital "Intellectual Capital: Its Application in Practice”, April 6-7, 2017, Portugal.

Hossain, M., Simula, H. and Halme, M. (2016), "Can frugal go global? Diffusion patterns of frugal innovations", Technology in Society, Vol. 46, pp. 132-139. https://doi.org/10.1016/j.techsoc.2016.04.005

ISO (2006), ISO 14040: Environmental management-Life cycle assessment: Principles and framework, International Standard Organisation (ISO), Geneva.

ISO (2009), Draft International Standard ISO/DIS 26000, Guidance on Social Responsibility, International Standard Organisation (ISO), Geneva.

Lund, R.T. (1996), The remanufacturing industry: Hidden giant, Boston University.

Mitchell, C.J.A. (1993), "Economic Impact of The Arts: Theatre Festivals In Small Ontario Communities", Journal of Cultural Economics, Vol. 17 No. 2, pp. 55-67.

National Library of France (n.d.), Collections de marionettes. [online] Gallica. Available at: http://gallica.bnf.fr/html/und/objets/collections-de-marionnettes-titre-page (accessed 09 decembre 2017).

Négrier, E. and Vidal, M. (2009), "L’impact économique de la culture: réel défi et fausses pistes", Economia della Cultura, Vol. 19, No. 4, pp. 487-498. 
Nissen, N.F., Griese, H., Middendorf, A., Müller, J., Pötter, H. and Reichl, H. (1997), “Comparison of simplified environmental assessments versus full life cycle assessment (LCA) for the electronics designer", Life Cycle Networks: Proceedings of the 4th CIRP International Seminar on Life Cycle Engineering, CIRP, Berlin, Germany, pp. 301-312.

Pialot, O., Millet, D. and Tchertchian, N. (2012), "How to explore scenarios of multiple upgrade cycles for sustainable product innovation: the "Upgrade Cycle Explorer" tool", Journal of Cleaner Production, Vol. 22, No. 1, pp. 19-31. https://doi.org/10.1016/j.jclepro.2011.10.001

Radjou, N., Prabhu, J., Ahuja, S. and Roberts, K. (2012), Jugaad Innovation: A Frugal and Flexible Approach to Innovation for the 21st Century, Random House India, New Delhi.

Rohmer, S., Mérat, A., Floderer, V. and Copinet, A. (2014), "Graph based method for the modelling of crumpled structures", Key Engineering Materials, Vol. 572, pp. 147-150. https://doi.org/10.4028/www.scientific.net/KEM.572.147

Tyl, B., Allais, R., Gobert, J., Bocken, N., Prendeville, S. and Pichler, P.P. (2015a), “Towards synergies between local repairers, citizens, designers, and public actors: the REVALUE project", GCPC conference, Stiges, Spain.

Tyl, B., Lizarralde, I. and Allais, R. (2015b), "Local value creation and eco-design: A new paradigm", Procedia CIRP, Vol. 30, pp. 155-160. https://doi.org/10.1016/j.procir.2015.02.024

UNESCO (2009), The 2009 UNESCO framework for cultural statistics

UNESCO and ITC (1997), International Symposium on Crafts and the International Market: Trade and Customs Codification: Final report, UNESCO and ITC.

Valkama, J. and Keskinen, M. (2008), “Comparison of simplified LCA variations for three LCA cases of electronic products from the ecodesign point of view", Proceedings of the 2008 IEEE International Symposium on Electronics and the Environment, ISEE '08, pp. 1-6.

Dr.-Ing. Romain Allais, research engineer

APESA, innovation

26 rue Hélène Boucher, 40220 TARNOS, France

Email: romain.allais@apesa.fr 